\title{
Cardiac Function Study
}

National Cancer Institute

\section{Source}

National Cancer Institute. Cardiac Function Study. NCI Thesaurus. Code C16094.

The study and analysis of the normal or abnormal functioning of the heart using methods such as echocardiography, exercise stress cardiography, 24-hour Holter EKG and magnetic resonance imaging. 